\title{
Are Plasma Thyroid-Stimulating Hormone Levels Associated with Degree of Obesity and Metabolic Syndrome in Euthyroid Obese Patients? A Turkish Cohort Study
}

\author{
Okan Bakiner, ${ }^{1}$ Emre Bozkirli, ${ }^{1}$ Gulhan Cavlak, ${ }^{1}$ Kursad Ozsahin, ${ }^{2}$ and Eda Ertorer ${ }^{1}$ \\ ${ }^{1}$ Department of Endocrinology and Metabolism Diseases, Faculty of Medicine, Baskent University, Dadaloglu Mah Serinevler, \\ 01250 Adana, Turkey \\ ${ }^{2}$ Department of Family Physician, Faculty of Medicine, Baskent University, Dadaloglu Mah Serinevler, 01250 Adana, Turkey
}

Correspondence should be addressed to Okan Bakiner; okanbakiner@mynet.com

Received 8 October 2013; Accepted 3 December 2013; Published 2 January 2014

Academic Editors: C.-H. Anderwald and A. Efanov

Copyright (C) 2014 Okan Bakiner et al. This is an open access article distributed under the Creative Commons Attribution License, which permits unrestricted use, distribution, and reproduction in any medium, provided the original work is properly cited.

\begin{abstract}
We aimed to observe the association between degree of obesity and metabolic syndrome and plasma thyrotropin levels in obese, euthyroid Turkish patients. 947 obese and overweight patients who admitted to our outpatient clinic were assessed retrospectively. 150 healthy euthyroid cases were also recruited as the control group. Cases with metabolic syndrome were determined. Patients were divided into various subgroups as overweight, obese, morbid obese, men, and women. No statistical significance was determined when all the patients' and subgroups' plasma thyrotropin levels were compared to normal weight control group. No association was shown between the presence of metabolic syndrome and plasma thyrotropin levels for both all patients and subgroups. Also there was not any association between each component of metabolic syndrome and plasma thyrotropin levels. In conclusion, we did not found any significant association between plasma thyrotropin levels and obesity and metabolic syndrome in our euthyroid subjects.
\end{abstract}

\section{Introduction}

Obesity is a serious health problem closely associated with insulin resistance and metabolic syndrome [1]. It has a complex pathophysiology characterized by interaction of genetic, environmental, and physiological factors [2]. Thyroid dysfunction is very well known to contribute to the pathogenesis of obesity. Weight loss is a common manifestation of hyperthyroidism and its treatment results in weight gain about four kilograms per year [3]. In contrast, weight gain is frequently seen in hypothyroidism and treatment causes mild weight loss [4]. The clinical observations mentioned above raise the questions of whether thyroid-stimulating hormone (TSH) change in physiological limits is associated with obesity and whether there is a link between adipose tissue and hypothalamo-thyroidal axis $[5,6]$. Some studies have shown positive correlation between obesity and plasma TSH levels in euthyroid subjects; nevertheless, conflicting studies are also present [7-10].
Metabolic syndrome is an important predictor of cardiovascular risk and is a cluster of abnormalities such as abdominal obesity, dyslipidemia, high plasma glucose, and hypertension [11]. Besides their impact on energy homeostasis, thyroid hormones are known to have a variety of effects on metabolic syndrome determinants [12-14]. There are some studies which show an association between thyroid hormone levels and metabolic syndrome in euthyroid patients, but the presence of counter studies creates discrepancy $[15,16]$. Conflicting results of different studies may be attributed to many contributing factors, such as ethnic differences, [17-23].

Herein, we aimed to determine the possible association among obesity, metabolic syndrome, and plasma TSH levels in our overweight or obese euthyroid cohort.

\section{Materials and Methods}

2.1. Patients and Methods. The participants of this retrospective study were the cases admitted to our outpatient clinic 
between January 2009 and April 2011 for obesity. Exhibiting a Body mass index (BMI) $\geq 25 \mathrm{~kg} / \mathrm{m}^{2}$ and plasma TSH levels between $0.3-5 \mathrm{mIU} / \mathrm{mL}$ were sought for inclusion. Cases with known thyroidal disease, history of thyroidectomy, accompanying endocrinological pathology, and/or history of receiving antithyroid medication, levothyroxine, or drugs which interact with thyroid functions were excluded. A group of 150 healthy euthyroid age- and gender-matched cases (31 males, 119 females) with BMI below 25 was included as control group.

Antropometric and blood pressure measurements, plasma TSH, simultaneous fasting plasma glucose, triglycerides, and high density lipoprotein cholesterol (HDL) levels of the patients were supplied from hospital records. For the control group, blood samples were taken early in the morning from antecubital vein after 12 hours of fasting. Arithmetical mean of three consecutive blood pressure measurements following five minutes of rest was recorded. Waist circumference was obtained from both suprailiac crests. Fastening body weight and height were measured and recorded. BMI values were calculated as $\mathrm{kg} / \mathrm{m}^{2}$. Body fat percentages of the patients were obtained early in the morning with TANITA BF300 foot to foot bicompartmental bioelectrical impedance technique after an overnight fasting following miction.

Plasma glucose was assayed using the enzymatic glucose oxidase method (Roche Modular, Roche Diagnostics GmbH, Mannheim, Germany) with intra- and interassay coefficients of variation (CVs) 1.0 and $1.7 \%$, respectively. The HDL cholesterol and triglycerides concentrations were determined enzymatically by cholesterol oxidase-peroxidase and glycerol phosphate dehydrogenase-peroxidase methods, respectively with the same autoanalyser and CVs less than $5 \%$.

Serum TSH levels were measured by chemiluminescence assay method using an Abbott-Architect analyser (Chicago, IL, USA). The CVs for intra- and interassay imprecision were $3 \%$ and $6 \%$, respectively.

The diagnosis of metabolic syndrome was performed using the National Cholesterol Education Program-Adult Treatment Panel III criteria [24].

2.2. Study Design. Patients were separated into subgroups according to BMI and gender as shown in Table 1. Healthy volunteers participating in the study $(n=150)$ were accepted as the control group. Plasma TSH levels of the control group were compared with all patients and subgroups. The association between plasma TSH levels and BMI, and waist circumference, and body fat percentages were investigated in all groups. The same procedure was performed for TSH levels and metabolic syndrome and its determinants, as well. Then, the TSH level $2.5 \mathrm{mIU} / \mathrm{mL}$ was accepted as a cut-off according to Wartofsky's data, the ones with TSH over this limit were accepted as high normal TSH group, whereas, the cases below this value as low normal TSH group [25]. The relationship between TSH and obesity and presence of metabolic syndrome was investigated between these two new TSH groups.
TABLE 1: Subgroups according to BMI and gender.

\begin{tabular}{lccc}
\hline Group & Name of group & BMI $\left(\mathrm{kg} / \mathrm{m}^{2}\right)$ & $n$ \\
\hline 1 & Overweight & $25-29.9$ & 133 \\
2 & Obese & $30-39.9$ & 330 \\
3 & Morbid obese & $\geq 40$ & 166 \\
4 & Men only & $\geq 25$ & 102 \\
5 & Women only & $\geq 25$ & 527 \\
\hline
\end{tabular}

2.3. Ethics. Baskent University ethics committee which conforms to the provisions of the Declaration of Helsinki in 1995 (as revised in Edinburgh 2000) approved the study protocol with the tracking number KA 12/279. Written informed consent was obtained from each healthy participant and patient anonymity was preserved for all subjects.

2.4. Statistical Analysis. Statistical analysis was performed using the statistical package SPSS v 17.0. For each continuous variable, normality was checked by the Kolmogorov-Smirnov and Shapiro-Wilk tests and by histograms. Comparisons between groups were applied using Student's $t$-test for normally distributed data and Mann-Whitney $U$ test was used for the data not normally distributed. The categorical variables between the groups were analyzed using the Chi-square test or Fisher Exc. test. A $P$ value of 0.05 was taken as the level of significance.

\section{Results}

A total of 947 patients were studied retrospectively and 629 patients were found to be eligible for inclusion. Demographic characteristics of the study and control groups were given in Table 2.

There were positive correlations between waist circumference and BMI, BMI and body fat percentage, and waist circumference and body fat percentage $(r=0.76, r=0.54$, $r=0.31$, for all $P=0.001$, resp.). There was a significant correlation between the presence of metabolic syndrome and waist circumference, BMI, and body fat percentage for all patients and all of the subgroups $(P=0.001)$.

No statistical significant difference was determined when group 1, group 2, and group 3 as well as whole patient group plasma TSH levels were compared to normal weight control group ( $P=0.34, P=0.69, P=0.12$, and $P=0.47$, resp.). Comparison of plasma TSH levels in subgroups was given in Table 3. There was no significant difference in subgroups according to plasma TSH levels.

Plasma TSH levels and anthropometric parameters did not exhibit any significant correlation in all patients and subgroups (Table 4).

No association was shown between the presence of metabolic syndrome and plasma TSH levels (Table 4). When association between each component of metabolic syndrome and plasma TSH levels was studied, no correlation was found (Table 5).

The data of high normal TSH group and low normal TSH group is given in Table 4. No significant difference was found 


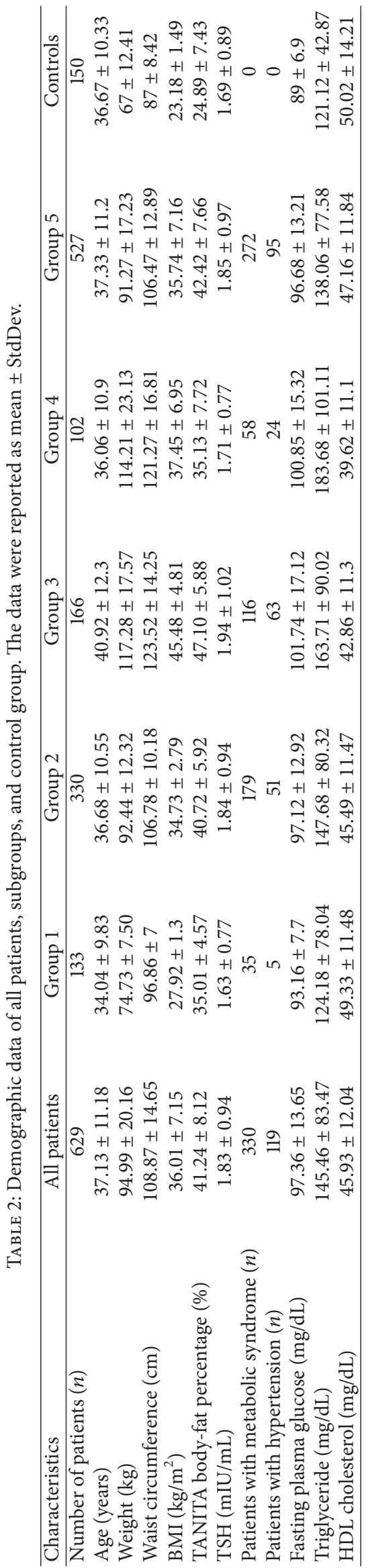


TABLE 3: Comparison of plasma TSH levels in subgroups. Results were given as $P$ value in each column. A $P$ value of 0.05 was taken as the level of significance.

\begin{tabular}{lcccccc}
\hline & Group 1 & Group 2 & Group 3 & Group 4 & Group 5 & Control \\
\hline Group 1 & - & 0.39 & 0.29 & 0.07 & 0.09 & 0.34 \\
Group 2 & 0.39 & - & 0.43 & - & 0.67 & 0.41 \\
Group 3 & 0.29 & 0.43 & 0.67 & - & 0.49 & 0.12 \\
Group 4 & 0.07 & 0.72 & 0.49 & 0.21 & 0.21 & - \\
Group 5 & 0.09 & 0.41 & 0.12 & 0.29 & 0.36 \\
\hline Control & 0.34 & 0.69 & & & - \\
\hline
\end{tabular}

TABLE 4: The association between anthropometric measures and plasma TSH levels for total-patient group and subgroups.

\begin{tabular}{|c|c|c|c|c|}
\hline Groups & $\begin{array}{c}\text { BMI-TSH } \\
\left(\mathrm{kg} / \mathrm{m}^{2}-\mathrm{mIU} / \mathrm{mL}\right)\end{array}$ & $\begin{array}{c}\text { Weight-TSH } \\
(\mathrm{kg}-\mathrm{mIU} / \mathrm{mL})\end{array}$ & $\begin{array}{c}\text { TANITA body fat percentage-TSH } \\
(\%-\mathrm{mIU} / \mathrm{mL}) \\
\end{array}$ & $\begin{array}{l}\text { Waist circumference-TSH } \\
(\mathrm{cm}-\mathrm{mIU} / \mathrm{mL})\end{array}$ \\
\hline \multirow{2}{*}{ All patients } & $r=0.054$ & $r=0.037$ & $r=0.023$ & $r=0.046$ \\
\hline & $P=0.28$ & $P=0.16$ & $P=0.81$ & $P=0.74$ \\
\hline \multirow{2}{*}{ Group 1} & $r=-0.15$ & $r=-0.154$ & $r=-0.123$ & $r=-0.054$ \\
\hline & $P=0.08$ & $P=0.22$ & $P=0.19$ & $P=0.064$ \\
\hline \multirow{2}{*}{ Group 2} & $r=-0.043$ & $r=-0.70$ & $r=-0.077$ & $r=-0.027$ \\
\hline & $P=0.43$ & $P=0.27$ & $P=0.09$ & $P=0.73$ \\
\hline \multirow{2}{*}{ Group 3} & $r=-0.39$ & $r=-0.417$ & $r=-0.005$ & $r=0.012$ \\
\hline & $P=0.36$ & $P=0.47$ & $P=0.81$ & $P=0.02$ \\
\hline \multirow{2}{*}{ Group 4} & $r=0.267$ & $r=0.235$ & $r=0.117$ & $r=0.17$ \\
\hline & $P=0.007$ & $P=0.017$ & $P=0.36$ & $P=0.09$ \\
\hline \multirow{2}{*}{ Group 5} & $r=0.027$ & $r=0.031$ & $r=0.01$ & $r=0.051$ \\
\hline & $P=0.077$ & $P=0.62$ & $P=0.56$ & $P=0.12$ \\
\hline
\end{tabular}

TABLE 5: The relationship between plasma TSH levels and the presence of metabolic syndrome and its components in all patients and subgroups.

\begin{tabular}{|c|c|c|c|c|c|}
\hline Groups & $\begin{array}{c}\text { TSH (mIU/mL)- } \\
\text { metabolic syndrome }\end{array}$ & $\begin{array}{l}\mathrm{TSH}(\mathrm{mIU} / \mathrm{mL}) \text {-fasting } \\
\text { plasma glucose }(\mathrm{mg} / \mathrm{dL})\end{array}$ & $\begin{array}{c}\mathrm{TSH}(\mathrm{mIU} / \mathrm{mL})- \\
\text { hypertension }\end{array}$ & $\begin{array}{c}\mathrm{TSH}(\mathrm{mIU} / \mathrm{mL})- \\
\text { triglyceride }(\mathrm{mg} / \mathrm{dL})\end{array}$ & $\begin{array}{c}\text { TSH }(\mathrm{mIU} / \mathrm{mL})-\mathrm{HDL} \\
\text { cholesterol }(\mathrm{mg} / \mathrm{dL})\end{array}$ \\
\hline All patients & $P=0.47$ & $\begin{array}{r}r=0.057 \\
P=0.24\end{array}$ & $P=0.49$ & $\begin{array}{c}r=0.052 \\
P=0.33\end{array}$ & $\begin{array}{c}r=-0.101 \\
P=0.011\end{array}$ \\
\hline Group 1 & $P=0.36$ & $\begin{array}{r}r=0.093 \\
P=0.61\end{array}$ & $P=0.36$ & $\begin{array}{r}r=0.041 \\
P=0.08\end{array}$ & $\begin{array}{c}r=-0.137 \\
P=0.86\end{array}$ \\
\hline Group 2 & $P=0.63$ & $\begin{array}{r}r=0.069 \\
P=0.06\end{array}$ & $P=0.17$ & $\begin{array}{l}r=0.021 \\
P=0.052\end{array}$ & $\begin{array}{c}r=-0.053 \\
P=0.49\end{array}$ \\
\hline Group 3 & $P=0.09$ & $\begin{array}{r}r=-0.052 \\
P=0.054\end{array}$ & $P=0.51$ & $\begin{array}{c}r=0.113 \\
P=0.91\end{array}$ & $\begin{array}{c}r=-0.144 \\
P=0.56\end{array}$ \\
\hline Group 4 & $P=0.16$ & $\begin{array}{c}r=0.074 \\
P=0.98\end{array}$ & $P=0.92$ & $\begin{array}{l}r=0.059 \\
P=0.048\end{array}$ & $\begin{array}{l}r=-0.23 \\
P=0.018\end{array}$ \\
\hline Group 5 & $P=0.27$ & $\begin{aligned} r & =0.6 \\
P & =0.23\end{aligned}$ & $P=0.63$ & $\begin{array}{l}r=0.051 \\
P=0.17\end{array}$ & $\begin{array}{c}r=-0.85 \\
P=0.49\end{array}$ \\
\hline
\end{tabular}

between anthropometric parameters of these new groups (Table 6). Similar number of patients in each group had metabolic syndrome $(P=0.37)$.

\section{Discussion}

In our euthyroid cohort, overweight, obese, morbid obese, and normal weight subjects did not demonstrate any association regarding BMI categories and plasma TSH levels. No association was detected between plasma TSH levels and the presence of metabolic syndrome, as well. This finding applied for both sexes. Cases with high normal and low normal TSH levels exhibited no difference in terms of obesity categories and metabolic syndrome.

Although the significant association between overt hypothyroidism and high adiposity has been demonstrated before, the issue is not clear for cases with TSH levels within normal limits [26]. A meta-analysis by Souza and Schieri showed that 18 studies out of 29 on this topic have demonstrated a significant association between plasma TSH 
TABLE 6: The data of the group with plasma TSH level $>2,5 \mathrm{mIU} / \mathrm{mL}$ (high normal TSH group) and of the group with plasma TSH level $<2,5 \mathrm{mIU} / \mathrm{mL}$ (low normal TSH group). The data were reported as mean \pm Standard deviation.

\begin{tabular}{|c|c|c|c|}
\hline Parameters & High normal TSH group & Low normal TSH group & $P$ \\
\hline Number of cases $(n)$ & 142 & 487 & 0.002 \\
\hline TSH (mIU/mL) & $3.25 \pm 0.61$ & $1.42 \pm 0.54$ & 0.003 \\
\hline $\operatorname{BMI}\left(\mathrm{kg} / \mathrm{m}^{2}\right)$ & $36.9 \pm 6.6$ & $35.7 \pm 7.2$ & 0.87 \\
\hline Body weight (kg) & $95.9 \pm 19.6$ & $94.7 \pm 20.3$ & 0.12 \\
\hline Waist circumference $(\mathrm{cm})$ & $109.3 \pm 13.7$ & $108.7 \pm 14.9$ & 0.65 \\
\hline Body fat percentage calculated with TANITA (\%) & $42.7 \pm 9.6$ & $40.9 \pm 7.5$ & 0.076 \\
\hline Cases with metabolic syndrome $(n)$ & 84 & 246 & 0.24 \\
\hline Fasting plasma glucose $(\mathrm{mg} / \mathrm{dL})$ & $99.1 \pm 15.3$ & $96.3 \pm 13.0$ & 0.63 \\
\hline Triglyceride (mg/dL) & $156.3 \pm 99.5$ & $142.2 \pm 77.9$ & 0.31 \\
\hline HDL cholesterol (mg/dL) & $44.2 \pm 10.3$ & $46.4 \pm 12.4$ & 0.19 \\
\hline Cases with hypertension $(n)$ & 25 & 94 & 0.061 \\
\hline
\end{tabular}

levels and adiposity, but those were not supported by the others [27]. In this meta-analysis, the correlation between TSH and obesity has been found in 11 of the clinical studies and it has been valid for both sexes in presence of morbid obesity and only for females in presence of obesity. As there are no different gender-specific cut-off values for normal plasma TSH, the correlation found only for obese women but not for men cannot be explained. Likewise, we could not find any correlation between BMI and plasma TSH levels for each gender.

Scientists supporting the idea that body adiposity correlates with increasing plasma TSH levels in euthyroid subjects have proposed that upper limit of normal TSH levels may be presumed as $2.5 \mathrm{mIU} / \mathrm{mL}$ and upper values may resemble subclinical hypothyroidism [25]. However in a wide population-based study conducted by Hamilton and coworkers, the upper limit of plasma TSH has been proposed as $4.0 \mathrm{mIU} / \mathrm{mL}$ for those with no thyroidal disease findings [28]. In accordance with this study, we did not determine any difference in terms of body adiposity when a TSH cut-off level $2.5 \mathrm{mIU} / \mathrm{mL}$ was used.

Some studies have pointed out the elevation of metabolic syndrome risk in euthyroid cases with the increasing TSH levels $[29,30]$. However, another study has shown no increase of metabolic syndrome incidence even in subclinical hypothyroidism [31]. In the present study, there was no correlation between plasma TSH levels and the presence of metabolic syndrome and each component of metabolic syndrome. Different results of different studies including ours may be related to distributional differences of groups, sensitivity of TSH measurement techniques, changes in reference cut-off points and race differences of normal serum TSH levels with definition of obesity, and metabolic syndrome [18-23].

Our study does not include free thyroid hormone levels, thyroid autoantibody levels, and lack of reevaluation for patients who lost weight after life style interventions which can be regarded as the pitfalls of the study. However plasma TSH assay seems to be the most useful laboratory test in the initial evaluation of thyroid disfunction in monitoring patients for thyroid disease. In addition, free thyroid hormone levels and autoantibody measurements are secondary diagnostic steps and are not mandatory for screening [32]. Our patients were admitted to the outpatient clinic for obesity and other parameters except TSH were not evaluated. Furthermore, this study was planned via retrospective data and follow-up findings are not included.

Absence of correlation between plasma TSH levels and obesity in the present study does not mean that TSH and thyroid hormones have no effect on adiposity. Recent studies have shown extrathyroidal TSH receptors on adipose tissue $[33,34]$. The TSH receptors found on rat preadipocytes have been demonstrated to play a role on adipocyte differentiation. Increasing TSH receptor expression in human subcutan adipose tissue has been shown to be parallel to the severity of obesity $[33,35]$. These findings suggest that TSH-adiposity interaction may be related to local TSH receptor expression rather than fluctuating plasma TSH levels. Dentice and coworkers have defined the importance of type II deiodinase activity for myogenesis and muscle regeneration [36]. Boelen and colleagues have reported that local deiodinase activity can change as an adaptation for differing situations and this may regulate the local effects of thyroid hormones [37]. Additionally, differences in local expressions of thyroid hormone receptors may be related to adipogenesis similar to local TSH receptor expression. Accordingly, it has been demonstrated that obese cases had a significant raise in thyroid hormone receptor alpha-1 gene expression in subcutaneous fat tissue compared to omental fat tissue [38].

Taking our results and the available medical literature into consideration, we think that the association between plasma TSH levels and obesity and metabolic syndrome may not be related to plasma hormone levels but probably to local hormone efficiency. Studies on local hormone effects in euthyroid obese models will clarify this issue.

\section{Abbreviations}

TSH: Thyroid-stimulating hormone

CVs: Coefficients of variation

HDL: High-density lipoprotein cholesterol

BMI: Body mass index. 


\section{Conflict of Interests}

The authors have no financial support or relationships that may pose a conflict of interests.

\section{References}

[1] S. E. Kahn, R. L. Hull, and K. M. Utzschneider, "Mechanisms linking obesity to insulin resistance and type 2 diabetes," Nature, vol. 444, no. 7121, pp. 840-846, 2006.

[2] D. W. Haslam and W. P. T. James, “Obesity," The Lancet, vol. 366, no. 9492, pp. 1197-1209, 2005.

[3] J. Dale, J. Daykin, R. Holder, M. C. Sheppard, and J. A. Franklyn, "Weight gain following treatment of hyperthyroidism," Clinical Endocrinology, vol. 55, no. 2, pp. 233-239, 2001.

[4] U. Kolyvanos Naumann, J. Furer, L. Käser, and W. Vetter, "Hypothyroidism. Main symptoms: fatigue, weight gain, depression, myalgia, edema," Praxis, vol. 96, no. 38, pp. 14111419, 2007.

[5] A. Schäffler, N. Binart, J. Schölmerich, and C. Büchler, "Hypothesis paper: brain talks with fat-evidence for a hypothalamicpituitary-adipose axis?" Neuropeptides, vol. 39, no. 4, pp. 363367, 2005.

[6] N. Pontikides and G. E. Krassas, "Basic endocrine products of adipose tissue in states of thyroid dysfunction," Thyroid, vol. 17, no. 5, pp. 421-431, 2007.

[7] M. A. Michalaki, A. G. Vagenakis, A. S. Leonardou et al., "Thyroid function in humans with morbid obesity," Thyroid, vol. 16, no. 1, pp. 73-78, 2006.

[8] G. Iacobellis, M. C. Ribaudo, A. Zappaterreno, C. V. Iannucci, and F. Leonetti, "Relationship of thyroid function with body mass index, leptin, insulin sensitivity and adiponectin in euthyroid obese women," Clinical Endocrinology, vol. 62, no. 4, pp. 487-491, 2005.

[9] N. Manji, K. Boelaert, M. C. Sheppard, R. L. Holder, S. C. Gough, and J. A. Franklyn, "Lack of association between serum TSH or free T4 and body mass index in euthyroid subjects," Clinical Endocrinology, vol. 64, no. 2, pp. 125-128, 2006.

[10] A. Svare, T. I. L. Nilsen, T. Bjøro, B. O. Åsvold, and A. Langhammer, "Serum TSH related to measures of body mass: longitudinal data from the HUNT Study, Norway," Clinical Endocrinology, vol. 74, no. 6, pp. 769-775, 2011.

[11] G. M. Reaven, "The metabolic syndrome: requiescat in Pace," Clinical Chemistry, vol. 51, no. 6, pp. 931-938, 2005.

[12] K. M. Kutty, D. G. Bryant, and N. R. Farid, "Serum lipids in hypothyroidism. A reevaluation," Journal of Clinical Endocrinology and Metabolism, vol. 46, no. 1, pp. 55-60, 1978.

[13] C. J. Torrance, J. E. Devente, J. P. Jones, and G. L. Dohm, "Effects of thyroid hormone on GLUT4 glucose transporter gene expression and NIDDM in rats," Endocrinology, vol. 138, no. 3, pp. 1204-1214, 1997.

[14] E. Fommei and G. Iervasi, "The role of thyroid hormone in blood pressure homeostasis: evidence from short-term hypothyroidism in humans," Journal of Clinical Endocrinology and Metabolism, vol. 87, no. 5, pp. 1996-2000, 2002.

[15] A. Roos, S. J. L. Bakker, T. P. Links, R. O. B. Gans, and B. H. R. Wolffenbuttel, "Thyroid function is associated with components of the metabolic syndrome in euthyroid subjects," Journal of Clinical Endocrinology and Metabolism, vol. 92, no. 2, pp. 491496, 2007.
[16] G. De Pergola, A. Ciampolillo, S. Paolotti, P. Trerotoli, and R. Giorgino, "Free triiodothyronine and thyroid stimulating hormone are directly associated with waist circumference, independently of insulin resistance, metabolic parameters and blood pressure in overweight and obese women," Clinical Endocrinology, vol. 67, no. 2, pp. 265-269, 2007.

[17] M. S. Morris, "The association between serum thyroid-stimulating hormone in its reference range and bone status in postmenopausal American women," Bone, vol. 40, no. 4, pp. 1128-1134, 2007.

[18] J. M. Schectman, G. A. Kallenberg, R. P. Hirsch, and R. J. Shumacher, "Report of an association between race and thyroid stimulating hormone level," American Journal of Public Health, vol. 81, no. 4, pp. 505-506, 1991.

[19] S. N. Wulan, K. R. Westerterp, and G. Plasqui, "Ethnic differences in body composition and the associated metabolic profile: a comparative study between Asians and Caucasians," Maturitas, vol. 65, no. 4, pp. 315-319, 2010.

[20] A. K. G. Tan, R. A. Dunn, and S. T. Yen, "Ethnic disparities in metabolic syndrome in Malaysia: an analysis by risk factors," Metabolic Syndrome and Related Disorders, vol. 9, no. 6, pp. 441451, 2011.

[21] S. X. Lin, M. Carnethon, M. Szklo, and A. Bertoni, "Racial/ethnic differences in the association of triglycerides with other metabolic syndrome components: the multi-ethnic study of atherosclerosis," Metabolic Syndrome and Related Disorders, vol. 9, no. 1, pp. 35-40, 2011.

[22] R. W. Taylor, L. Brooking, S. M. Williams et al., "Body mass index and waist circumference cutoffs to define obesity in indigenous New Zealanders," American Journal of Clinical Nutrition, vol. 92, no. 2, pp. 390-397, 2010.

[23] E. Bozkirli, M. E. Ertorer, O. Bakiner, N. B. Tutuncu, and N. G. Demirag, "The validity of the World Health Organisation's obesity body mass index criteria in a Turkish population: a hospital-based study," Asia Pacific Journal of Clinical Nutrition, vol. 16, no. 3, pp. 443-447, 2007.

[24] “Third Report of the National Cholesterol Education Program (NCEP) Expert Panel on Detection, Evaluation, and Treatment of High Blood Cholesterol in Adults (Adult Treatment Panel III) final report.National Cholesterol Education Program (NCEP) Expert Panel on Detection, Evaluation, and Treatment of High Blood Cholesterol in Adults (Adult Treatment Panel III) et al," Circulation, vol. 106, no. 25, pp. 3143-3421, 2002.

[25] L. Wartofsky and R. A. Dickey, "The evidence for a narrower thyrotropin reference range is compelling," Journal of Clinical Endocrinology and Metabolism, vol. 90, no. 9, pp. 5483-5488, 2005.

[26] L. Portmann and V. Giusti, "Obesity and hypothyroidism: myth or reality?” Revue Medicale Suisse, vol. 3, no. 105, pp. 859-862, 2007.

[27] A. D. M. Souza and R. Sichieri, "Association between serum TSH concentration within the normal range and adiposity," European Journal of Endocrinology, Supplement, vol. 165, no. 1, pp. 11-15, 2011.

[28] T. E. Hamilton, S. Davis, L. Onstad, and K. J. Kopecky, “Thyrotropin levels in a population with no clinical, autoantibody, or ultrasonographic evidence of thyroid disease: implications for the diagnosis of subclinical hypothyroidism," Journal of Clinical Endocrinology and Metabolism, vol. 93, no. 4, pp. 1224-1230, 2008. 
[29] Y. Lai, J. Wang, F. Jiang et al., "The relationship between serum thyrotropin and components of metabolic syndrome," Endocrine Journal, vol. 58, no. 1, pp. 23-30, 2011.

[30] A. C. Waring, N. Rodondi, S. Harrison et al., "Thyroid function and prevalent and incident metabolic syndrome in older adults: the health, ageing and body composition study," Clinical Endocrinology, vol. 76, no. 6, pp. 911-918, 2012.

[31] J. D. J. Garduño-Garcia, U. Alvirde-Garcia, G. López-Carrasco et al., "TSH and free thyroxine concentrations are associated with differing metabolic markers in euthyroid subjects," European Journal of Endocrinology, vol. 163, no. 2, pp. 273-278, 2010.

[32] J. R. Garber, R. H. Cobin, H. Gharib et al., "Clinical practice guidelines for hypothyroidism in adults: cosponsored by the american association of clinical endocrinologists and the american thyroid association," Thyroid, vol. 22, no. 12, pp. 1200-1235, 2012.

[33] K. Haraguchi, H. Shimura, L. Lin, T. Endo, and T. Onaya, "Differentiation of rat preadipocytes is accompanied by expression of thyrotropin receptors," Endocrinology, vol. 137, no. 8, pp. 3200-3205, 1996.

[34] A. Sorisky, A. Bell, and A. Gagnon, "TSH receptor in adipose cells," Hormone and Metabolic Research, vol. 32, no. 11-12, pp. 468-474, 2000.

[35] S. Lu, Q. Guan, Y. Liu et al., "Role of extrathyroidal TSHR expression in adipocyte differentiation and its association with obesity," Lipids in Health and Disease, vol. 11, article 17, 2012.

[36] M. Dentice, A. Marsili, R. Ambrosio et al., "The FoxO3/type 2 deiodinase pathway is required for normal mouse myogenesis and muscle regeneration," Journal of Clinical Investigation, vol. 120, no. 11, pp. 4021-4030, 2010.

[37] A. Boelen, J. Kwakkel, and E. Fliers, "Beyond low plasma T3: local thyroid hormone metabolism during inflammation and infection," Endocrine Reviews, vol. 32, no. 5, pp. 670-693, 2011.

[38] F. J. Ortega, J. M. Moreno-Navarrete, V. Ribas et al., "Subcutaneous fat shows higher thyroid hormone receptor- $\alpha 1$ gene expression than omental fat," Obesity, vol. 17, no. 12, pp. 21342141, 2009. 


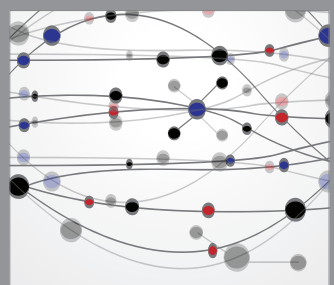

The Scientific World Journal
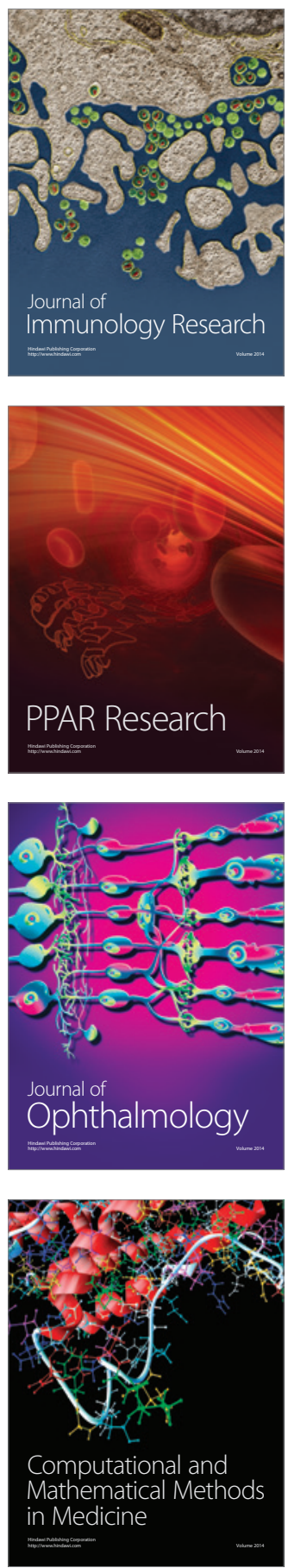

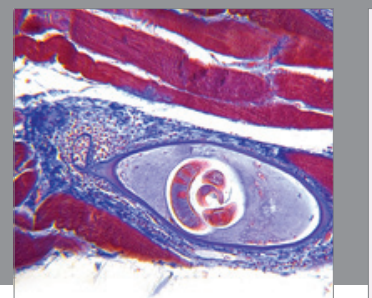

Gastroenterology

Research and Practice
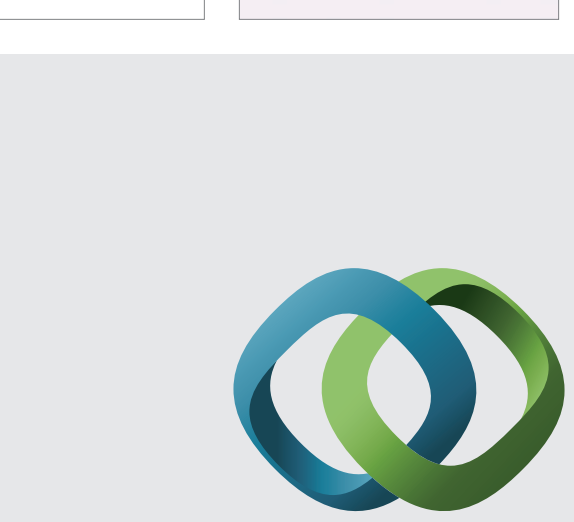

\section{Hindawi}

Submit your manuscripts at

http://www.hindawi.com
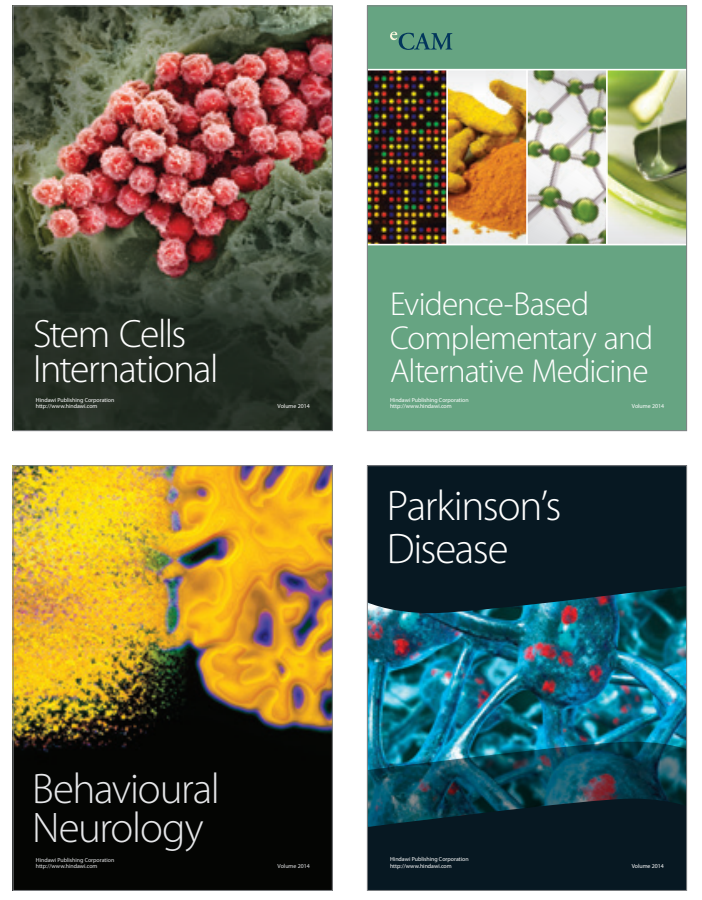
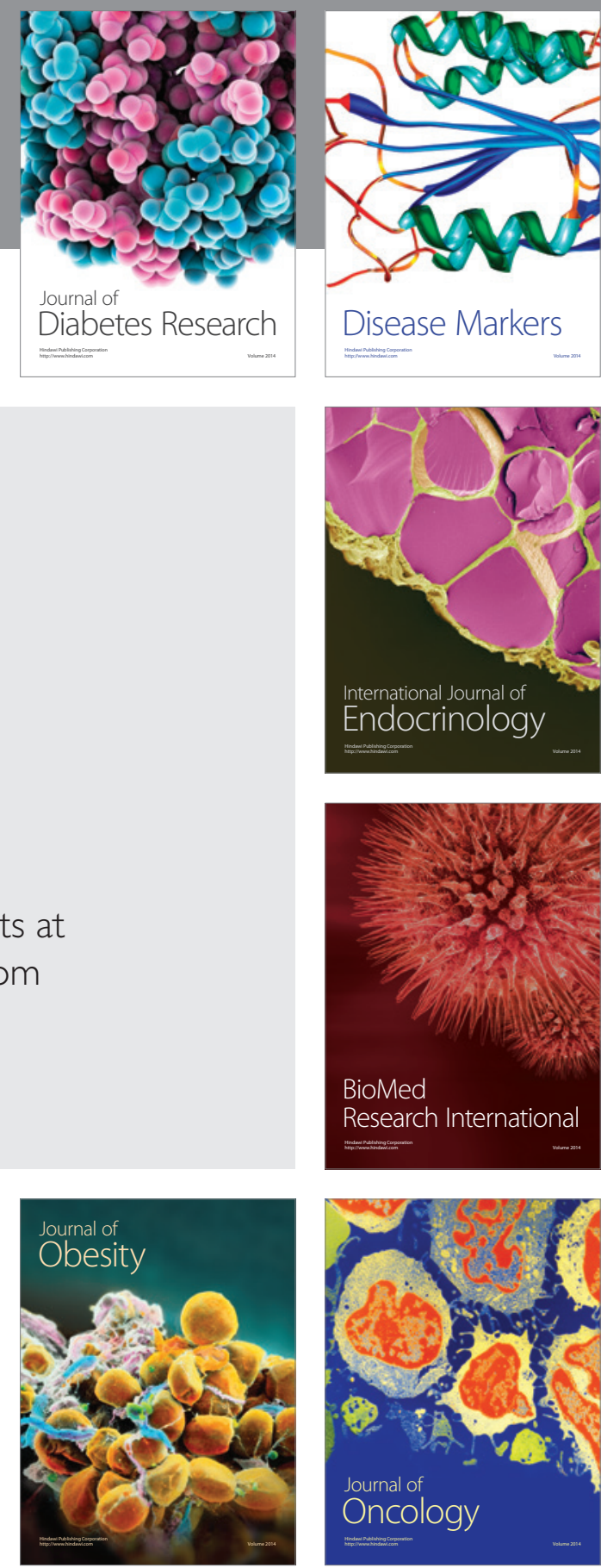

Disease Markers
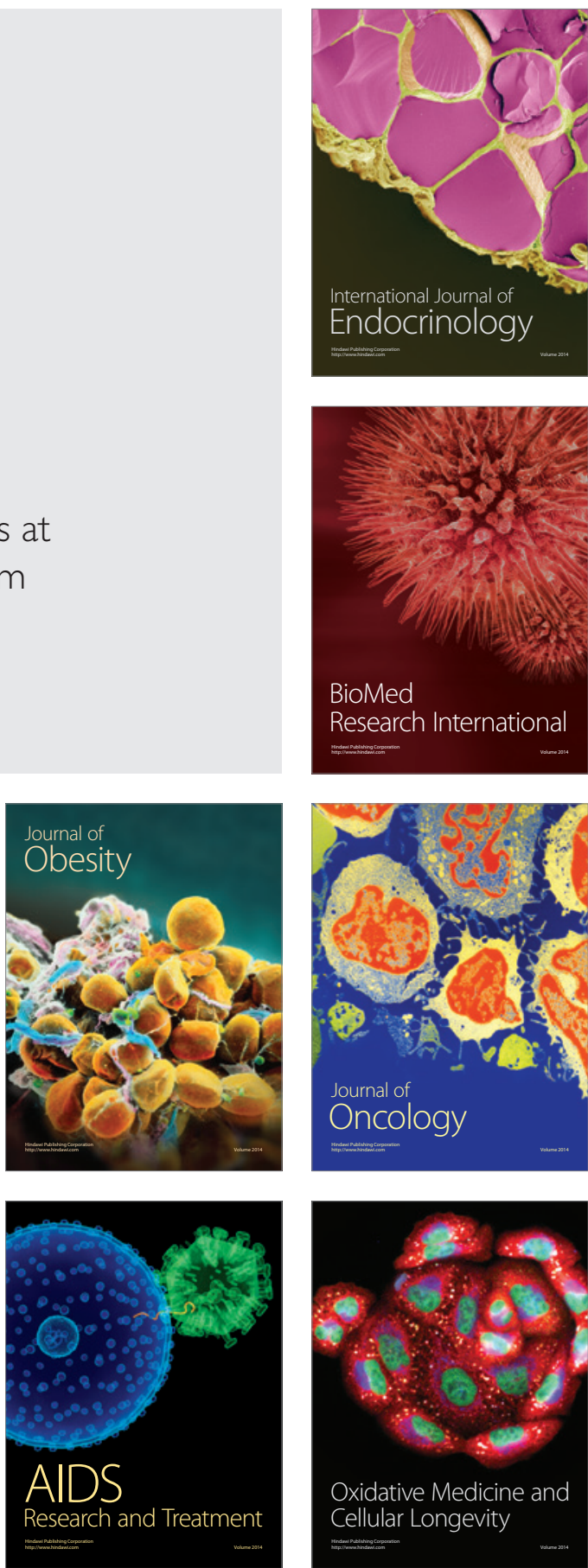